\title{
EL DISCURSO DE LA JURAMENTACIÓN PRESIDENCIAL EN REPÚBLICA DOMINICANA (1963-1912)
}

\author{
Fabio Abreu ${ }^{1}$
}

\section{Reseña de libro}

Inicio esta reseña en medio de pronunciamientos de sectores sociales que marchan en las calles de Santo Domingo, República Dominicana, con pancartas y camisetas, exigiendo que no haya más impunidad y que se castigue la corrupción en torno al caso de la empresa constructora brasileña Odebrecht. Asimismo, sectores eclesiales reclaman al gobierno y al Congreso que detengan la despenalización del aborto. Ambas manifestaciones de protesta tienen de fondo una petición: recordarle al presidente — y a la justicia dominicana - el juramento, consignado en la Constitución, que hizo al asumir la presidencia.

Este libro, de la autoría de los doctores Manuel Matos Moquete y Reina Rosario, publicado por el fondo editorial del INTEC en 2014 (280 páginas), versa sobre los discursos de juramentación presidencial a lo largo del proceso de evolución de la democracia dominicana (1963-2012). Muestra un recorrido analítico, un amplio paseo por la cultura política y lingüística de los expresidentes en su afán estratégico por ganar la confianza de la ciudadanía

1. Profesor del Instituto Tecnológico de Santo Domingo (INTEC), República Dominicana. Dirección electrónica: fabioabreu69@gmail.com para garantizar la gobernabilidad. En la mayoría de sus discursos ha predominado un borrón y cuenta nueva o una ruptura con las propuestas de la campaña electoral.

Esta obra es la tercera investigación del proyecto Estrategia de captación y dominación de la voluntad popular en los discursos politicos dominicanos, auspiciada por la universidad del INTEC. El primer autor de la obra, el Dr. Manuel Matos Moquete, ha desarrollado una vasta experiencia analítica de las producciones discursivas sociales y políticas a través del Centro de Lingüística Aplicada. Su marco de análisis se sitúa en la semántica, la oratoria y la pragmática, cuyo eje es el discurso como evento comunicativo sociopolítico y la lingüística de la enunciación.

En el año 2007, este autor publicó el libro Estrategias de captación de la voluntad popular en las elecciones del 2004. Siguiendo la temática, en 2009 difundió su obra Propuestas, valores e ideologías en el discurso politico dominicano (1963-2008). Por su parte, la profesora e historiadora Reina Rosario ha investigado sobre los temas de migración haitiana e identidad dominicana, haciendo un aporte a la investigación desde el análisis de los referentes históricos. 
Esta obra pretende — según sus autores - analizar las estrategias de persuasión y comunicación en los discursos de juramentación, teniendo en cuenta los auditorios como constructos del orador. El corpus del análisis está compuesto por 14 discursos de los presidentes dominicanos desde 1963 hasta 2012. Presenta una mirada multidisciplinaria y translingüística, propia de la metodología de la disciplina del Análisis del Discurso (AD). La retórica, la pragmática, la lingüística cognitiva y las ciencias sociales son integradas en dicho análisis. Por eso, se recrean varias voces de interlocutores, sobre todo, académicos que aportaron sus puntos de vista sobre las interpretaciones de estos discursos de juramentación.

En los discursos analizados se muestran las relaciones intersubjetivas que intentaron construir los presidentes con los auditorios. Es una tarea difícil y compleja, esto debido a la diversidad de intencionalidades que se entrecruzan e intervienen, tanto desde los autores del discurso como desde los auditorios presenciales, radiales y televisivos. En consecuencia, los autores quisieron limitar su quehacer analítico a tres dimensiones del discurso: la dimensión interactiva sociocultural, uso del lenguaje, y la cognición (marco conceptual de los discursos).

A partir de esas tres dimensiones, el libro está dividido en cuatro capítulos. En el capítulo uno, se expone de forma general el contexto retórico-pragmático que enmarca el estudio de los discursos de juramentación. También, se destaca la influencia protocolar en la producción discursiva, así como la apelación a Dios mediante el uso de citas de presidentes pertenecientes a un contexto más amplio que el dominicano.

En el capítulo dos los autores se adentran en el contexto sociohistórico. Ofrecen una panorámica sucinta de los grandes momentos que sirvieron de soporte a los catorce discursos de juramentación, así como la reacción de la población dominicana, la cual quedó documentada a través de una bibliografía histórica.

El capítulo tres está destinado a analizar la interacción social, considerada como eje del acto comunicativo.
Se describen los acuerdos socio-cognitivos que hacen posible el intercambio político, cuyos matices son diversos. Todo depende de la imagen del productor del discurso: los créditos del orador. Cada imagen es analizada desde la subjetividad manifiesta del orador en el discurso, por ejemplo, la imagen del poder. Los autores llaman la atención sobre una estrategia protocolar común entre todos los exponentes del discurso. Se trata de la cortesía empleada para lograr la efectividad de la interacción.

En el capítulo cuatro se describe y analiza la organización de los discursos. Dos aspectos básicos son tomados en cuenta, el plan de exposición y la referencia al juramento. El primero, nos permite conocer la cultura lingüística de los oradores y evaluar sus comportamientos discursivos y expresivos. El segundo aspecto aparece en el inicio del plan del discurso. Es el acto por excelencia, el cual destaca la intertextualidad y la actitud particular de cada orador frente al compromiso que proclama asumir. Además, se presentan elementos importantes para la comprensión del acto de juramentación como el Nunca antes, cuya estructura expositiva es común a los catorce discursos analizados.

Finalmente, el capítulo cinco está dedicado al análisis argumentativo, considerado por los autores como el más significativo y característico de este tipo de discurso. Es señalado, siguiendo la acepción de Aristóteles, como discurso epidíctico, también es institucional. Se analiza el sistema argumentativo propio de cada discurso, destacando aspectos comunes y divergentes entre pares de oradores, como Joaquín Balaguer y Juan Bosch, los cuales forjaron liderazgos comunicativos como maestros de la política criolla.

En general, la obra constituye una referencia analítica valiosa para los estudios del discurso político en República Dominicana, y hasta ahora es única en su género. En ella, el liderazgo político obtendría indicadores referenciales estratégicos para enfilar sus discursos de juramentación, pero también para cumplirlos. 